\title{
Targeted Research
}

National Cancer Institute

\section{Source}

National Cancer Institute. Targeted Research. NCI Thesaurus. Code C19334.

Research funded as a result of an institute set aside of dollars for a specific scientific area. Institutes solicit applications using research initiatives (RFAs for grants, RFPs for contracts). Targeted research applications are reviewed by chartered peer review committees within institutes. The opposite of Investig ator-initiated research. 